\title{
Shoe Cleasing and Sprucing Apparatus
}

\author{
Sanjay Kumar, Ajay Kumar, Raj Kumar
}

\begin{abstract}
The present invention relates to shoe cleansing and sprucing apparatus. As all the office employees, factory workers wear shoes, hence there is a need to clean dust and other unwanted slit material which enters into the office or laboratory along with user shoes. Therefore, the shoe cleaning and sprucing apparatus not only provide a cleaning action to the shoes of customer but also cleans the environment by cleaning the dust from the surface. It is portable, cost effective, requires less maintenance and it is easy in construction.
\end{abstract}

\section{INTRODUCTION}

It is said that "Cleanliness is next to godliness". The developed apparatus that is designed and manufactured by us is called as "shoe heel cleaner with shoe polishing apparatus", with the help to this apparatus the shoe can be clean and polish or spruce without taking much time and effort [1].

In today's world mostly every industry and schools have laboratory like research lab, medical lab, instrument lab, OPT and various restricted cites of government laboratories like testing labs etc. Most of the problems in the laboratories are caused by the dirty and untidy shoes wearer by the employees of these industries and laboratories. It will cause hazardous to the present environment. Therefore, it is requiring to make a clean and eco-friendly environment by cleansing and sprucing the shoe. The apparatus should provide complete protection and cleanliness to the shoe heel and polishing of shoe. As per major standing is given to the boot choice these days, one should also pay attention in preservation also in nearly areas or zones orderly atmosphere is chosen, henceforth washing of shoe, higher and lower portion of shoe and similarly to have stylish appearance or look to the mankind, cleansing of the boot is essential, bearing in mind all these aspects wide-ranging variety of devices for boot or shoe heel cleansing and shoe sprucing has been grew up from unadventurous periods of time and moreover this paper presents a series of thoughts of the merchandise and benefits in choosing an advanced structure for shoe heel cleansing and shoe sprucing apparatus [2],[3],[4].

\section{THOUGHT DEVELOPMENT METHOD}

A thought development method is a order of stages or actions that associate grade enterprise hires to consider, plan, and commercialize a invention [5],[6]. Several of those stages and process are knowledgeable and structure rather

Revised Version Manuscript Received on 10 September, 2019.

Sanjay Kumar, Department of Mechanical Engineering, Noida Institute of Engineering and Technology, UttarPradesh, India.

(Email: researchnietip@gmail.com)

Ajay Kumar, Department of Mechanical Engineering, Noida Institute of Engineering and Technology, UttarPradesh, India.

(Email: researchnietip@gmail.com)

Raj Kumar, Department of Mechanical Engineering, Noida Institute of Engineering and Technology, UttarPradesh, India.

(Email: researchnietip@gmail.com) than of physical. Few administrations describe and survey a detailed and complete development process, whereas others might not be able to define the processes. Also, each and every group employs a procedure at minimum slightly diverse from that of each other group. In fact, continuous enterprise might track totally dissimilar procedures for to each and every types of advance inventions.

The Thought development method comprises the subsequent procedure as given below in block diagram,

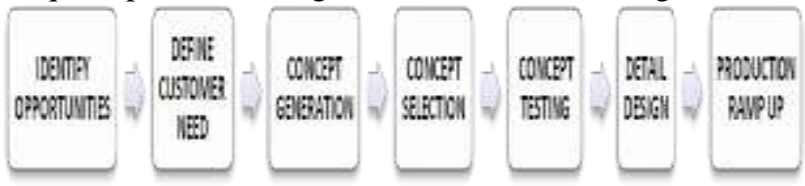

Fig2.1: Thought development procedure block diagram

\section{DESIGNING OF CLEANSING AND SPRUCING APPARATUS}

a: First conceptual structure:

The schematic diagram for shoe cleansing and shoe sprucing drawn in 3-dimensional CAD is shown below in Fig 3.1 .

In this figure3.1, the apparatus describes the boot or shoe heel cleansing (removal of dirt in addition to other undesirable solid attached to the heel) as well as benefits in sprucing the shoe [7],[8].

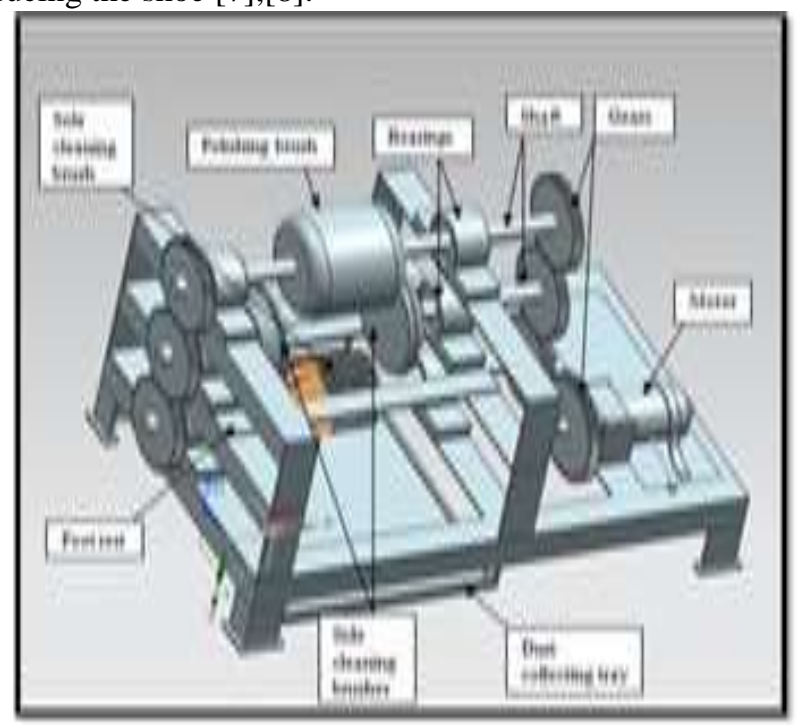

Fig 3.1: Primary concept structure (a) for shoe heel cleansing with sprucing apparatus. 
b: secondary conceptual structure:

The diagram of the secondary concept structure (b) for Shoe heel cleansing with sprucing apparatus is as shown through a three-dimensional CAD structure in Fig 3.2.

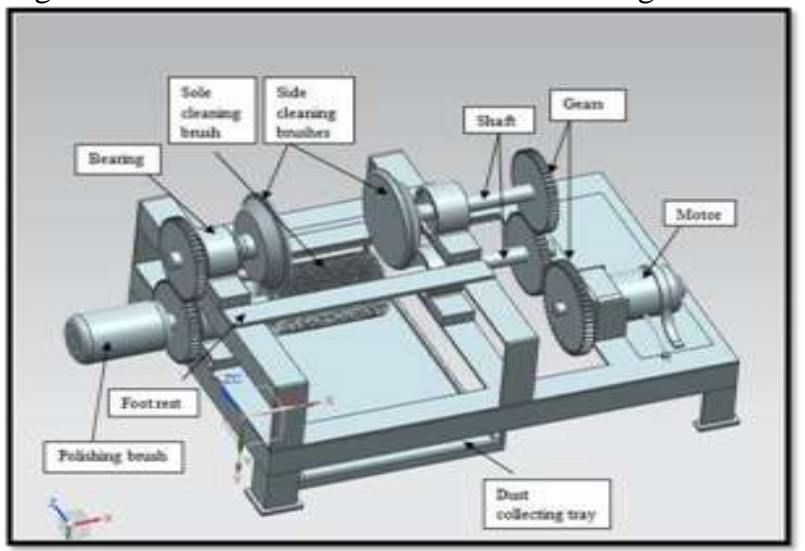

Fig 3.2: Secondary concept structure (b) for shoe heel cleansing with sprucing apparatus

The concept structure (b) is planned in command to overcome the disadvantages of the conceptual structure (a). In the fig 3.2, the apparatus describes the shoe heel cleaning (eliminating of dirt, silt and any additional undesirable material attached to the heel) and also helps in sprucing the shoe.

Concept (b) provides simple operation of each shoes heel cleansing and sprucing wherever in sprucing operation is provided exterior of the apparatus that helps the user to easily passage the boot over the spinning broom. The sprucing fluid is placed physically to the shoe throughout the sprucing operation. Entire gears, shaft and bearings stands are restored on the iron block support settled to carry out the operation, at the lowermost a plate is provided so as to gather the mud elements found throughout the process of heel cleansing.

\section{GEOMETRICAL CONFIGURATION \& RESULTS}
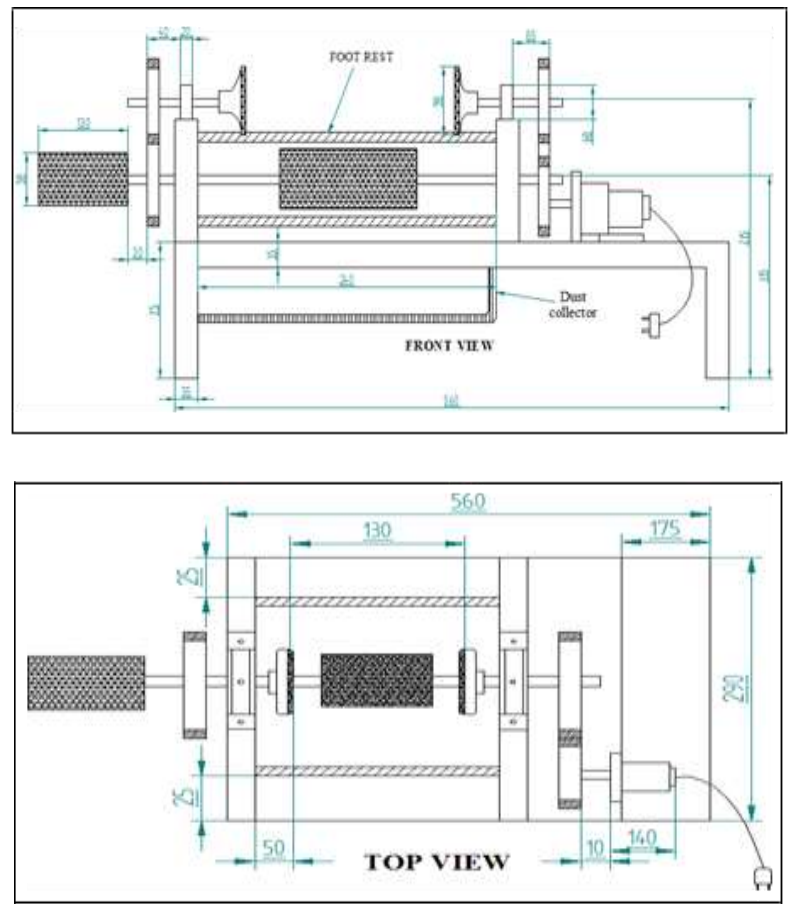

Fig 4.1: Comprehensive 2-d view (Front View and Top
View) of the accumulated structure

\section{CALCULATION OF DESIGNED APPRATUS}

We have used single shaft, that carries the only real cleansing broom and sprucing broom, and therefore the bearing supporting the shaft at individual locations. For the turning of shaft essential gear train are organized in order to attain the motion and the development of the apparatus to neat and clean the shoe with polishing it. For having a harmless action of the apparatus, the shaft must be designed, assuming the masses and forces acting on it. Hence the shaft designed is protected [9],[10],[11].

Its own weight of $2 \mathrm{~kg}$, and over-all weight of $15.51 \mathrm{~N}$ for the shaft is supposed.

From Design statistics book we have, $\mathrm{Fs}=2$, $\sigma \mathrm{ed}=137.96$ Mpa, $\sigma y=309.9$ Mpa.

Speed available at the shaft:

We know that

$\frac{\mathrm{n}_{1}}{\mathrm{n}_{2}}=\frac{\mathrm{z}_{2}}{\mathrm{z}_{1}}$

Where $\mathrm{n} 1=219 \mathrm{rpm}, \mathrm{z} 2=96, \mathrm{z} 1=96 \mathrm{n} 2=219 \mathrm{rpm}$.

The shaft is exposed to mutual twisting and torsion. Therefore, the shaft diameter can be written as,

$\therefore \mathrm{D}=\left\{\left(\frac{16}{\pi * \tau_{\text {ed }}}\right)\left\{\left(\mathrm{K}_{\mathrm{b}} * \mathrm{M}_{\mathrm{b}}\right)^{2}+\left(\mathrm{K}_{\mathrm{t}} * \mathrm{M}_{\mathrm{t}}\right)^{2}\right\}^{1 / 2}\right\}^{1 / 3}$

Supposing steady or step by step practical load we've got, $\mathrm{K}_{\mathrm{z}}=1, \mathrm{~K}_{\mathrm{b}}=1.5$

Loads which is acting on shaft.

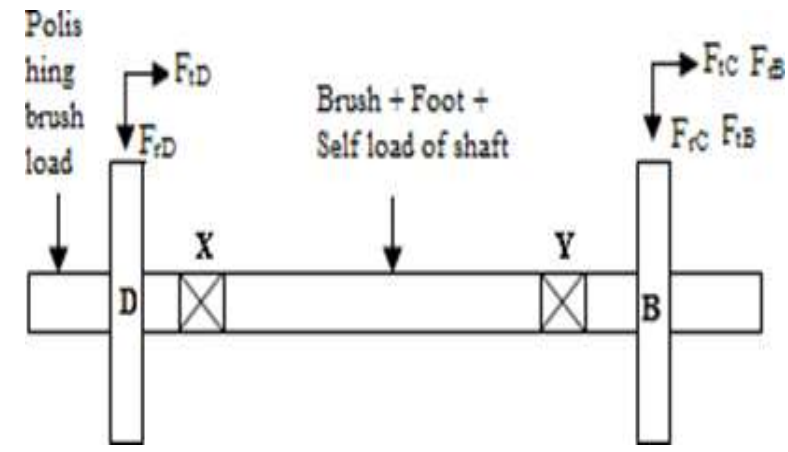

Fig 5.1: Numerous loads stand-in on the shaft

As on the Fig.5.1, the gear is riding on shaft, and consist of the bearing support on the shaft, the load of broom, apparatus own load and shoe load is focused at middle of the shaft seeing at point $\mathrm{c} F r$ and $\mathrm{Ft}$ are radial and tangential projection load, in which the forces are acting and deciding it to achieve the extreme bending moment, and hereafter the diameter of the shaft [11].

\section{Shaft power-}

Transferred torque

$$
\mathrm{M}_{\mathrm{t}}=\frac{9550 * \mathrm{~N} * 1000}{\mathrm{n}}
$$

here Mt in $\mathrm{N}-\mathrm{mm}$, watt $\mathrm{N}=15 \mathrm{~W}$, motor speed $\mathrm{n} 1=200$ rpm.

$$
\begin{aligned}
& \therefore \mathrm{M}_{\mathrm{t} 1}=\frac{9550 * 0.015 * 10}{200} \\
& \text { the gear at position } b
\end{aligned}
$$




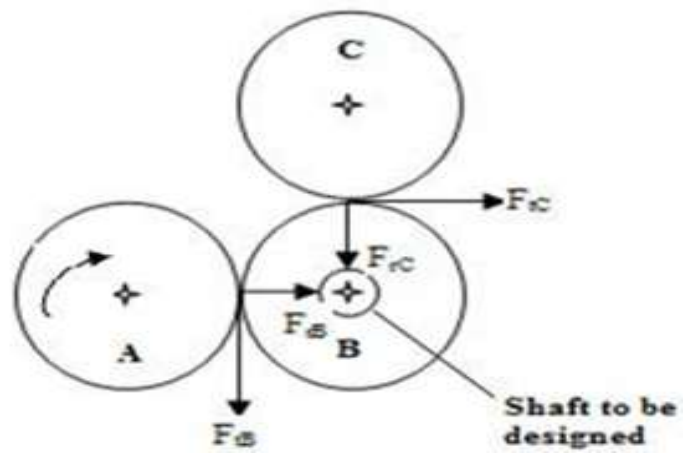

Fig 5.2: FBD of the loads at the gear position $b$

The direction of rotation of gear (a) is in clockwise and the direction of rotation of gear (b) is anticlockwise.

$$
\begin{aligned}
& \mathrm{r}_{g B}=\frac{d_{g B}}{2}=\frac{100}{2}=50 \mathrm{~mm} \\
& \mathrm{M}_{t 1}=\mathrm{F}_{t B} * \mathrm{r}_{g B} \\
& 716.25=\mathrm{F}_{t B} * 50 \\
& \therefore \mathrm{F}_{t B}=14.32 \mathrm{~N} \\
& \therefore \mathrm{F}_{r B}=\mathrm{F}_{t B} * \tan \varphi=14.32 * \tan 20=5.21 \mathrm{~N}
\end{aligned}
$$

the torque which is transferred from gear $\mathrm{c}$, is shown by Fig 5.2,

$$
\mathrm{M}_{22}=\frac{9550 * \mathrm{~N} * 1000}{\mathrm{n}_{2}}=\frac{9550 * 0.015 * 1000}{219}=654.10 \mathrm{~N}-1
$$

Hence,

$\mathrm{r}_{g B}=\frac{d_{g B}}{2}=\frac{100}{2}=50 \mathrm{~mm}$

Also,

$$
\begin{aligned}
& \mathrm{M}_{t 2}=\mathrm{F}_{t C} * \mathrm{r}_{g B} \\
& 654.10=\mathrm{F}_{t C} * 50 \\
& \therefore \mathrm{F}_{t C}=13.08 \mathrm{~N} \\
& \therefore \mathrm{F}_{\mathrm{rC}}=\mathrm{F}_{t C} * \tan \varphi=13.08 * \tan 20=4.76 \mathrm{~N}
\end{aligned}
$$

the gear at the position $d$

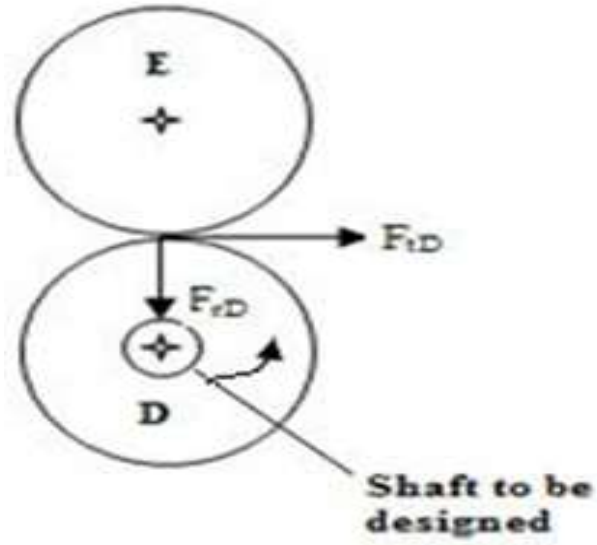

Fig 5.3: FBD of the loads at the gear position $d$

Here, the direction of rotation of gear (e) is in clockwise and the direction of rotation of gear (d) is anticlockwise.

$\mathrm{r}_{g D}=\frac{d_{g D}}{2}=\frac{100}{2}=50 \mathrm{~mm}$

Also,

$$
\begin{aligned}
& \mathrm{M}_{t 1}=\mathrm{F}_{t D} * \mathrm{r}_{g D} \\
& 716.25=\mathrm{F}_{t D} * 50 \\
& \therefore \mathrm{F}_{t D}=14.32 \mathrm{~N} \\
& \therefore \mathrm{F}_{t D}=\mathrm{F}_{t D} * \tan \varphi=14.32 * \tan 20=5.21 \mathrm{~N}
\end{aligned}
$$

Thus,

The forces acting on the shaft horizontally due to gear $\mathrm{b}$ and $\mathrm{d}$ are $\mathrm{FtD}=12.03 \mathrm{~N}, \mathrm{FtC}=12.03 \mathrm{~N}, \mathrm{FrB}=6.11 \mathrm{~N}$.

The forces acting on the shaft vertically due to gear $\mathrm{b}$ and $\mathrm{d}$ are $\mathrm{FrD}=3.95 \mathrm{~N}, \mathrm{FrC}=3.95 \mathrm{~N}, \mathrm{FtB}=12.55 \mathrm{~N}$.

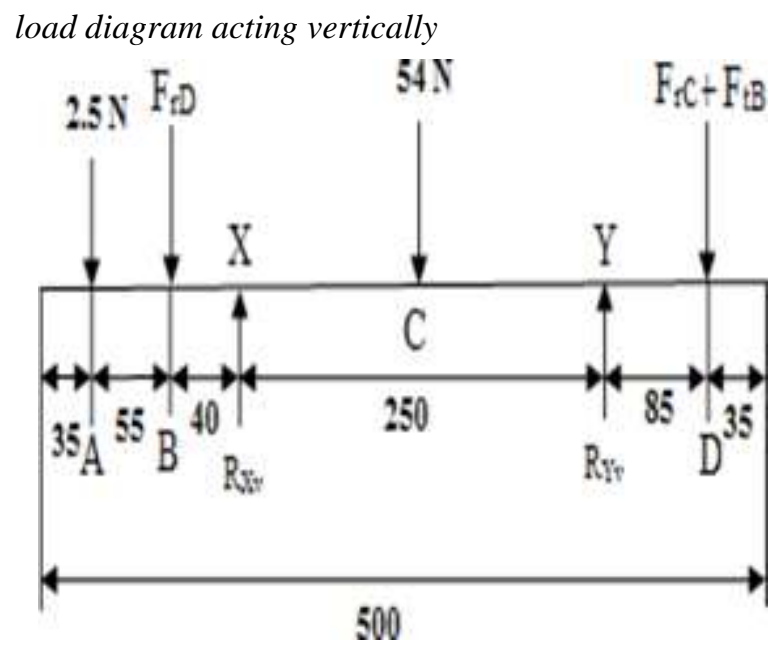

Fig 5.4: load diagram acting vertically to shaft

Suppose RXv and RYv is the bearing responses to vertical loads acting, and forces is shown by Fig. 5.4, in which, FrD $=3.95 . \mathrm{N}$,

$\mathrm{FrC}+\mathrm{FtB}=3.95+12.55=16.10 \mathrm{~N}$, at $\mathrm{b}$ and $\mathrm{d}$.

And at $\mathrm{b}=$ gear $\mathrm{d}$ and $\mathrm{at} \mathrm{d}=$ gear $\mathrm{b}$ is pointed, own weight of the shaft $=2 \mathrm{~kg}=16.72 \mathrm{~N}$,

Weight of the heel cleaning broom $=0.9 \mathrm{~kg}=8.62 \mathrm{~N}$, and the load acting due to base placed on the broom $=3.5 \mathrm{~kg}=$ $30.42 \mathrm{~N}$.

Over-all load stand-in on shaft due to broom, own load of shaft and base load $=16.10+8.62+30.42=55.64 \sim 56 \mathrm{~N}$ at the midpoint 'c'[10],[3].

From the Fig,

Moment about ' $\mathrm{x}$ '

$\mathrm{R}_{\mathrm{Yv}} * 250=125 * 54+165 * 4.76+220 * 2.5+19.08 * 335$

$\mathrm{R}_{\mathrm{YV}}=\frac{14477.2}{250}$

$\therefore \mathrm{R}_{\mathrm{Yv}}=57.90 \mathrm{~N}$

$\mathrm{R}_{\mathrm{Yv}}+\mathrm{R}_{\mathrm{Xv}}=2.5+4.76+54+19.08$

$\therefore \mathrm{R}_{\mathrm{Xv}}=22.44 \mathrm{~N}$

the vertical axis bending moment $(\mathrm{BM})$ is find by $\mathrm{BM}$ at $\mathrm{X}=0 . \mathrm{BM}$ at $\mathrm{Y}=0$.

$\mathrm{BM}$ at $\mathrm{A}=\mathrm{RXv} * 95=2131.8 \mathrm{~N}-\mathrm{mm} . \mathrm{BM}$ at $\mathrm{B}=\mathrm{RXv} *$ $40=897.6 \mathrm{~N}-\mathrm{mm} . \mathrm{BM}$ at $\mathrm{C}=\mathrm{RYv} * 125=7237.5 \mathrm{~N}-\mathrm{mm}$. $\mathrm{BM}$ at $\mathrm{D}=\mathrm{RYV} * 85=4921.5 \mathrm{~N}-\mathrm{mm}$.

the horizontal load diagram is shown as 


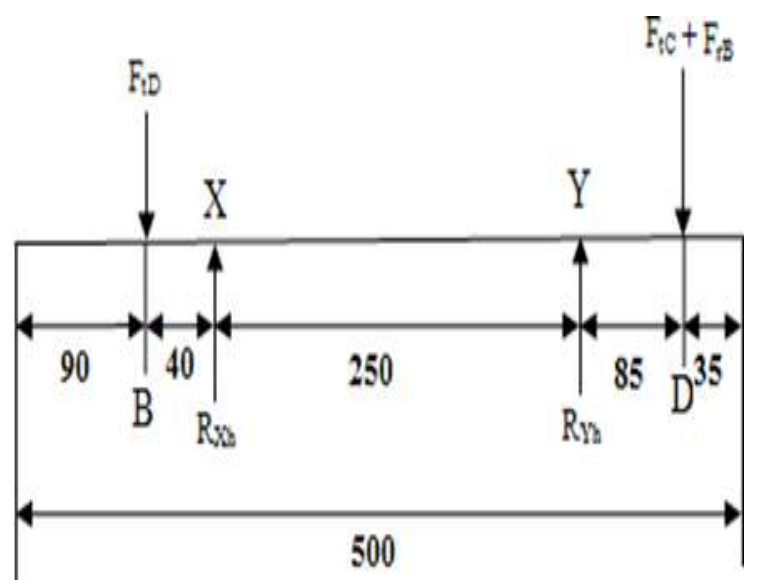

Fig 5.5: loads diagram which is acting horizontally on the shaft

Suppose RXv and RYv is the bearing responses to vertical loads acting, and forces is shown by Fig. 5.4, in which, FtD $=12.01 . \mathrm{N}$,

$\mathrm{FtC}+\mathrm{FrB}=13.016 .04=19.02 \mathrm{~N}$ at the position $\mathrm{b}$ and $\mathrm{d}$. And, at position $b=$ the gear $d$ and at position $d=$ the gear $b$ is pointed.

In Fig,

The BM about ' $\mathrm{x}$ '

$\mathrm{R}_{\mathrm{Yh}} * 250=18.29 * 335+13.08 * 40$

$\mathrm{R}_{\mathrm{Yh}}=\frac{6650.35}{250}$

$\therefore \mathrm{R}_{\mathrm{Yh}}=26.60 \mathrm{~N}$

$\mathrm{R}_{\mathrm{Yh}}+\mathrm{R}_{\mathrm{Xh}}=18.29+13.08$

$\therefore \mathrm{R}_{\mathrm{Xh}}=4.77 \mathrm{~N}$

To find horizontal bending moment (BM)

$\mathrm{BM}$ at $\mathrm{X}=0 \mathrm{BM}$ at $\mathrm{Y}=0$

$\mathrm{BM}$ at $\mathrm{B}=\mathrm{RXh} * 40=190.8 \mathrm{~N}-\mathrm{mm}$.

$\mathrm{BM}$ at $\mathrm{D}=\mathrm{RYh} / 85=2261 \mathrm{~N}-\mathrm{mm}$.

\section{Resultant bending moment}

$\mathrm{BM}$ at $\mathrm{X}=0 \mathrm{BM}$ at $\mathrm{Y}=0$

$\mathrm{BM}$ at $\mathrm{A}=2131.8 \mathrm{~N}-\mathrm{mm}$.

$\mathrm{BM}$ at $\mathrm{B}=\sqrt{2131.8^{2}+190.8^{2}}=2140.32 \mathrm{~N}-\mathrm{mm}$

$\mathrm{BM}$ at $\mathrm{C}=7237.5 \mathrm{~N}-\mathrm{mm}$

$\mathrm{BM}$ at $\mathrm{D}=\sqrt{2261^{2}+897.6^{2}}=2432.65 \mathrm{~N}-\mathrm{mm}$.

From above values we have,

Maximum bending moment $\mathrm{Mb}=7237.5 \mathrm{~N}-\mathrm{mm}$.

Maximum twisting moment $\mathrm{Mt}=716.25 \mathrm{~N}-\mathrm{mm}$.

The shaft diameter which is subjected to bending and twisting is given by,

$$
D=\left\{\left(\frac{16}{\pi * \tau_{e d}}\right)\left\{\left(K_{b} * M_{b}\right)^{2}+\left(K_{t} * M_{t}\right)^{2}\right\}^{1 / 2}\right\} 1 / 3
$$

Substitute the value of diameter in directly above equation,

$$
\begin{aligned}
& D=\left\{\left(\frac{16}{\pi * 82.776}\right)\left\{(1.5 * 7237.5)^{2}+(1 * 716.25)^{2}\right\}^{1 / 2}\right\}^{1} \\
& \therefore \mathrm{D}=8.74 \sim 9 \mathrm{~mm}
\end{aligned}
$$

The accepted diameter is $19 \mathrm{~mm}$, obtained is $8.74 \mathrm{~mm}$. Hence $8.74 \mathrm{~mm}<19 \mathrm{~mm}$, thus it can be said that the design is protected.

\section{CONCLUSIONS}

The fast speed spin of the broom benefits in cleansing the heel of the boot or shoes efficiently and the spinning broom integrated to the similar shaft aids in sprucing the shoes and the oil is physically put by operator at surface of boot or shoes. Hence the shoe heel cleansers are tremendously beneficial in the areas where the dirt due to the sleepers, boot or shoes is a main problem. The shoe heel cleansing with sprucing apparatus is a complete system manufactured for cleansing the shoe for the purpose to eliminate dust and make a dirt less environment and also sprucing the shoe for giving a stylish appearance to the footwear along with the handler. Therefore, it is concluded that the practice of shoe heel cleansing with sprucing apparatus is very important machine for all the employees either working in industries or offices and also in institutions where purity and hygiene atmosphere is a principal objective.

\section{REFERENCES}

1. A. E. Musa and G. A. Gasmelseed, "Combination tanning system for manufacture of shoe upper leathers: Cleaner tanning process," J. Soc. Leather Technol. Chem., 2012.

2. I. Lihtețchi, R. Sava, and M. Lihtețchi, "Innovative Solutions for a Shoe Heel Cleaner," Appl. Mech. Mater., 2014.

3. M. Simon, "Turing Apparatuss," in Automata Theory, 2012.

4. "Design and development of automatic shoe cleaning and polishing apparatus with liquid spraying shoe ink," Int. J. Mod. Trends Eng. Res., 2017.

5. J. ALBORS-GARRIGOS, "Innovation Management and New Product Development. By Paul Trott," $R \& D$ Manag., 2009.

6. J. C. Narver, S. F. Slater, and D. L. MacLachlan, "Responsive and Proactive Market Orientation and New-Product Success*," J. Prod. Innov. Manag., 2004.

7. H. Mintzberg, "The Fall and Rise of Strategic Planning," Harv. Bus. Rev., 1994.

8. J. G. Smith, "Rise and fall of strategic planning," Long Range Plann., 1994.

9. J. J. Uicker, G. R. Pennock, J. E. Shigley, and J. M McCarthy, "Theory of Apparatuss and Mechanisms," $J$. Mech. Des., 2003.

10. A. D. Brickman, "Theory of apparatuss," J. Mech., 2005.

11. M. Kolovsky, A. Evgrafov, Y. Semenov, A. Slousch, and Z. Dybczak, "Advanced Theory of Mechanisms and Apparatuss," Appl. Mech. Rev., 2002. 